\title{
Imaging of Oxidation-Specific Epitopes in Atherosclerosis and Macrophage-Rich Vulnerable Plaques
}

\author{
Karen C. Briley-Saebo • Young Seok Cho • \\ Sotirios Tsimikas
}

Published online: 1 December 2010

(C) The Author(s) 2010. This article is published with open access at Springerlink.com

\begin{abstract}
Oxidative stress, and in particular oxidation of lipoproteins, is a hallmark of atherosclerosis. Upon entry of lipoproteins into the vessel wall, a cascade of proatherogenic pathways is initiated whereby the reaction of reactive oxygen species with substrates amenable to oxidation, such as polyunsaturated fatty acids, generates a variety of oxidation-specific epitopes on lipoproteins, proteins in the vessel wall, and apoptotic macrophages. Several of these oxidation-specific epitopes have been well characterized and specific murine and fully human antibodies have been generated in our laboratory to detect them in the vessel wall. We have developed radionuclide, gadolinium and iron oxide based MRI techniques to noninvasively image oxidation-specific epitopes in atherosclerotic lesions. These approaches quantitate plaque burden and also allow detection of atherosclerosis regression and plaque stabilization. In particular, gadolinium micelles or lipid-coated ultrasmall superparamagnetic iron oxide particles containing oxidation-specific antibodies accumulate within macrophages in the artery wall, suggest-
\end{abstract}

K. C. Briley-Saebo

Translational and Molecular Imaging Institute,

Department of Radiology, Mount Sinai School of Medicine,

New York, NY, USA

e-mail: Karen.saebo@mountsinai.org

Y. S. Cho

Seoul National University College of Medicine,

28 Yongon,

Seoul 110-744, South Korea

e-mail: flammeus@snubh.org

Y. S. Cho $\cdot$ S. Tsimikas $(\bowtie)$

Vascular Medicine Program, University of California San Diego, 9500 Gilman Drive, BSB 1080,

La Jolla, CA 92093-0682, USA

e-mail: stsimikas@ucsd.edu ing they may image the most unstable plaques. Translation of these approaches to humans may allow a sensitive technique to image and monitor high-risk atherosclerotic lesions and may guide optimal therapeutic interventions.

Keywords Atherosclerosis · Lipoproteins · Oxidation · Antibody $\cdot$ Radionuclide imaging $\cdot$ Radioisotopes $\cdot$ Magnetic resonance imaging

\section{Introduction}

Oxidative stress represents an imbalance between the production and degradation of reactive oxygen species (ROS), such as superoxide anion or hydrogen peroxide created by myeloperoxidase, nitric oxide synthase, NADPH oxidase, xanthine oxidase, and other oxidases $[1 \bullet 2,3 \bullet]$. Hyperlipidemia, inflammatory conditions, or endothelial injury can cause increased ROS production, which can modify fatty acids, lipoproteins, and amino acids, thereby generating oxidation-specific epitopes (OSE). The characterization of oxidation of low-density lipoprotein (OxLDL) is a classic example of the consequences of a pro-oxidant and proinflammatory environment, generating a variety of OSE, such as the well-described oxidized phospholipid (OxPL) and malondialdehyde (MDA) epitopes on LDL [4, 5]. These OSE are biologically active by upregulating adhesion molecules to attract monocytes into the vessel wall, can mediate proinflammatory responses in cytokines and upregulation of pro-inflammatory genes, mediate macrophage retention and apoptosis, and are cytotoxic. OSE are pro-atherogenic by mediating the unregulated uptake of OxLDL in macrophages through scavenger receptors and generating activated macrophage foam cells. Furthermore, OSE are potent immunogens and can activate 


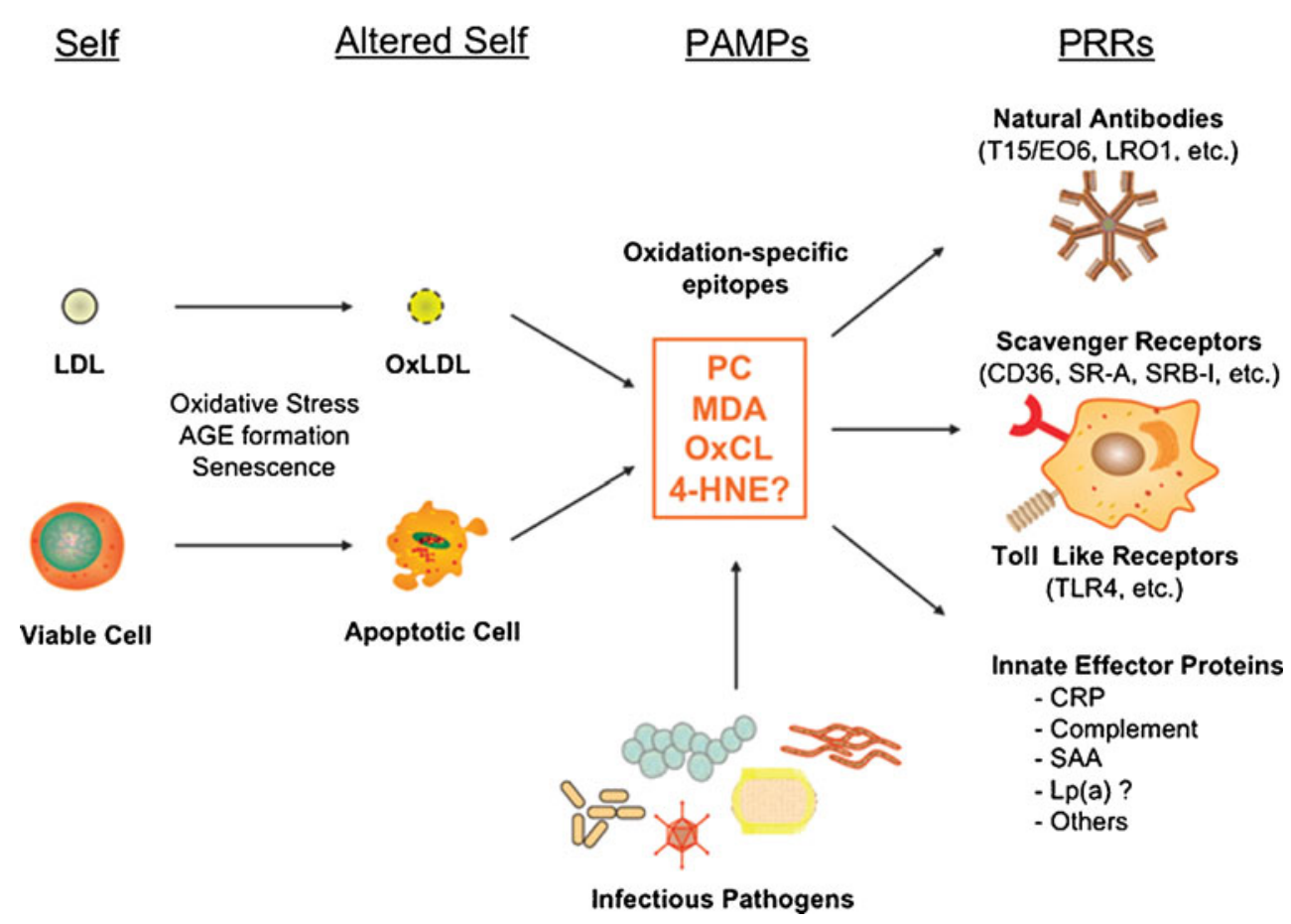

Fig. 1 Oxidation-specific epitopes are a class of pathogen-associated molecular patterns (PAMPs) that are recognized by natural antibodies and other innate immune receptors. Physiological and pathological stress can lead to the generation of oxidation-specific epitopes (altered self) on membranes of lipoproteins as well as cells (self), which are subsequently recognized by natural antibodies, scavenger receptors, and other innate effector proteins via these motifs. In many, if not all,

$\mathrm{T}$ cells and B cells, resulting in the generation of autoantibodies directed to unique OSE that can be present on lipids and proteins such as on OxLDL, lipoprotein (a) [Lp(a)], within macrophage foam cells, on proteins in the extracellular matrix, and on the surface of apoptotic cells $[6 \cdot \bullet]$.

It is now widely accepted that atherosclerosis is a chronic inflammatory disease and does not simply result cases, molecular mimicry exists between oxidation-specific epitopes of self-antigens and epitopes of infectious pathogens. 4-HNE, 4hydroxynonenal; AGE, advanced glycation end product; CRP, Creactive protein; $\mathrm{Lp}(\mathrm{a})$, lipoprotein [a]; MDA, malondialdehyde; OxCL, oxidized cardiolipin; OxLDL, oxidized LDL; PC, phosphorylcholine; SAA, serum amyloid A. (Reprinted with permission from Hartvigsen et al. $[6 \bullet \bullet])$

from the bland accumulation of lipids [7]. The nature of the inflammatory response includes the interaction of antigens, such as OSE, and immune cells such as monocyte/macrophages, T cells, and $\mathrm{B}$ cells. OSE can be regarded as a major target of many innate pattern recognition receptors, which are preformed, germline-encoded receptors, and presumably the product of natural selection. These OSE
Fig. 2 The left panel displays an illustration of LDL that is modified by a variety of oxidation-specific epitopes, including phosphocholinecontaining oxidized phospholipids (oxPC), malondialdehyde (MDA and 4-hydroxynonenal [HNE] epitopes). The right panel displays an illustration of an $\mathrm{IgG}$ antibody showing its various effector functions. MDA2, E06, and IK17 are well-characterized oxidation-specific antibodies

\section{"oxidation-specific" epitopes}

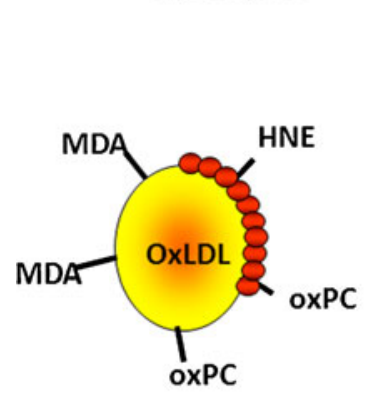

\section{"oxidation-specific" antibodies}

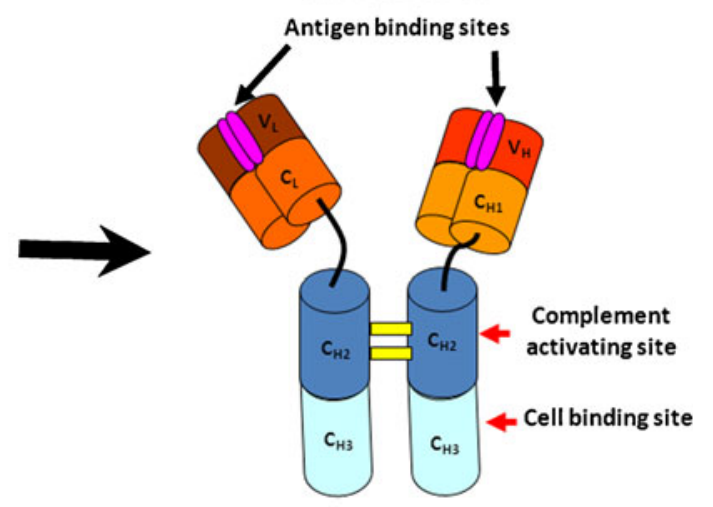

E06, MDA2 - murine monoclonal AB

IK-17 - human monoclonal Fab or scFv 
are ubiquitous in atherosclerotic lesions and represent "danger signals," thus constituting a class of pathogenassociated molecular patterns, which have led to the natural selection of multiple innate pattern recognition receptors that target such epitopes. This includes both cellular pattern recognition receptors, such as scavenger receptors and tolllike receptors (TLRs) on macrophages, and soluble pattern recognition receptors, such as natural antibodies. The finding that natural antibodies secreted from OxLDLspecific B-cell lines bind to oxidation-specific epitopes, block uptake of OxLDL by macrophages, recognize apoptotic cells, and are deposited in atherosclerotic lesions suggested a new role of innate immunity and pathogenassociated molecular patterns (Fig. 1) [6••].
Taking advantage of the biological and immunological properties of OSE, we have generated, characterized, and evaluated murine and human monoclonal antibodies as imaging agents. In this review, we will describe imaging of atherosclerosis and macrophages using oxidation-specific antibodies.

\section{Antibodies to Oxidation-Specific Epitopes}

MDA2

MDA2 is a murine monoclonal $\operatorname{IgG}$ type antibody specific for MDA-lysine epitopes. It binds MDA-LDL, and other
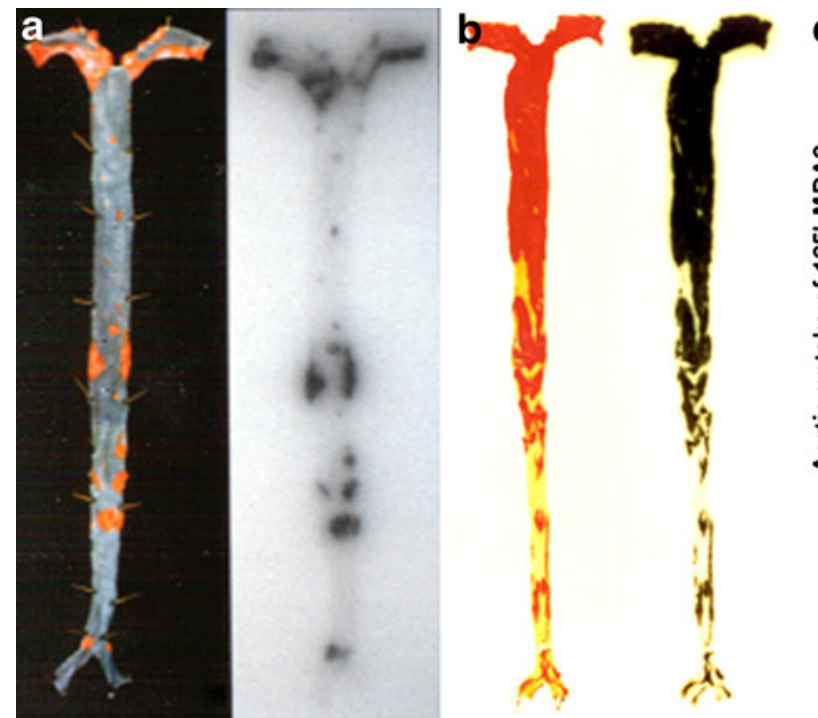

\section{C}

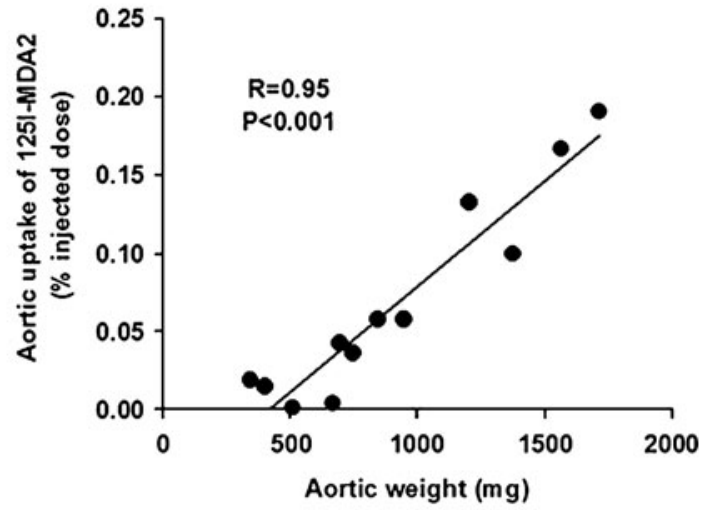

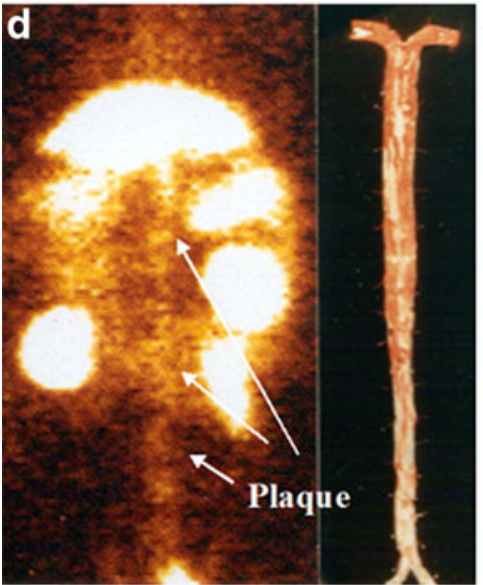

WHHL

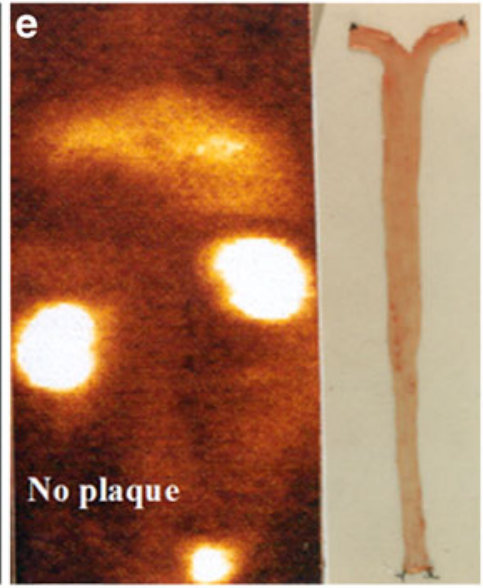

NZW

Fig. 3 En-face preparations of Sudan-stained aortas from an apoE $E^{-/-}$ mouse (a) and a Watanabe heritable hyperlipidemic (WHHL) rabbit (b) injected with ${ }^{125}$ I-MDA2. Red color (left panels in a and b) signifies the presence of neutral lipid within the atherosclerotic plaque stained with Sudan IV, and black color (right panels in a and b) in the corresponding autoradiograph signifies the presence of accumulated ${ }^{125}$ I-MDA2 reflecting the presence of MDA-lysine epitopes. Panel $\mathbf{C}$ shows the relationship of ${ }^{125}$ I-MDA2 uptake and plaque burden as measured by aortic weight. A similar relationship is present with percent atherosclerosis surface area. Panels $\mathbf{d}$ and $\mathbf{e}$ represent in vivo imaging of atherosclerotic WHHL (d) and nonatherosclerotic New Zealand white (e) rabbits with ${ }^{99 \mathrm{~m}} \mathrm{Tc}-\mathrm{MDA} 2$. (Reprinted with permission from Tsimikas et al. [9], [10•]) 
MDA-modified proteins, but not native LDL, high-density lipoprotein, or very low-density lipoprotein [8]. MDA2 immunostains MDA-lysine epitopes in various stages of atherosclerotic lesions, particularly early fatty streaks in humans and intermediate lesions of mice and rabbits [9, $10 \bullet, 11 \bullet \cdot]$.

\section{E06}

E06 is a natural IgM autoantibody cloned from apolipoprotein E-deficient mice $\left(\mathrm{apoE}^{-/-}\right.$) that binds to the phosphocholine (PC) head group of oxidized but not normal phospholipids [12]. E06 binds to PC of oxidized phospholipids when it is exposed as a result of conformational changes induced by oxidative modification of polyunsaturated fatty acid at the sn-2 position of phospholipids. E06 blocks the uptake of OxLDL and apoptotic cells by macrophages [13]. Interestingly, E06 is structurally and functionally identical to classic "natural" murine T15 antiPC antibodies that are of B-1 cell origin and are reported to provide optimal protection from virulent pneumococcal infection [14]. This suggests that T15/E06 evolved through natural selection from B-1 cells and their physiological role may be in immune defense and housekeeping roles against PC-containing organisms, clearance of PC-containing apoptotic cells, and protection against oxidation-dependent changes $[6 \bullet, 15]$.

\section{IK17}

IK17 is a human monoclonal $\operatorname{IgG}$ antibody fragment (used either as a Fab fragment or single chain Fv fragment for imaging purposes) binding to MDA-LDL and copper OxLDL [16]. The exact chemical structure of the epitope it recognizes is not fully defined, but it appears to be an MDA-like epitope that is expressed during extensive oxidative modification. IK17 was isolated from a phage display library from a patient with coronary artery disease with high plasma autoantibody titers to MDA-LDL. IK17 also inhibits the uptake of OxLDL and apoptotic cells by macrophages. Because IK17 is a human autoantibody it has potential advantages in imaging over murine antibodies to OSE, including improved pharmacokinetics and reduced immunologic reactions [16]. Figure 2 displays the concepts of oxidation-specific epitopes as antigens and imaging targets and oxidation-specific antibodies as the targeting agents.

In a recent study in human vulnerable plaques, we demonstrated that OSE were absent in normal coronary arteries. Early lesions immunostained for all epitopes but the overall extent was minimal. However, as lesions progressed, the presence of apoB and MDA epitopes did not increase, whereas OxPL and IK17 epitopes increased
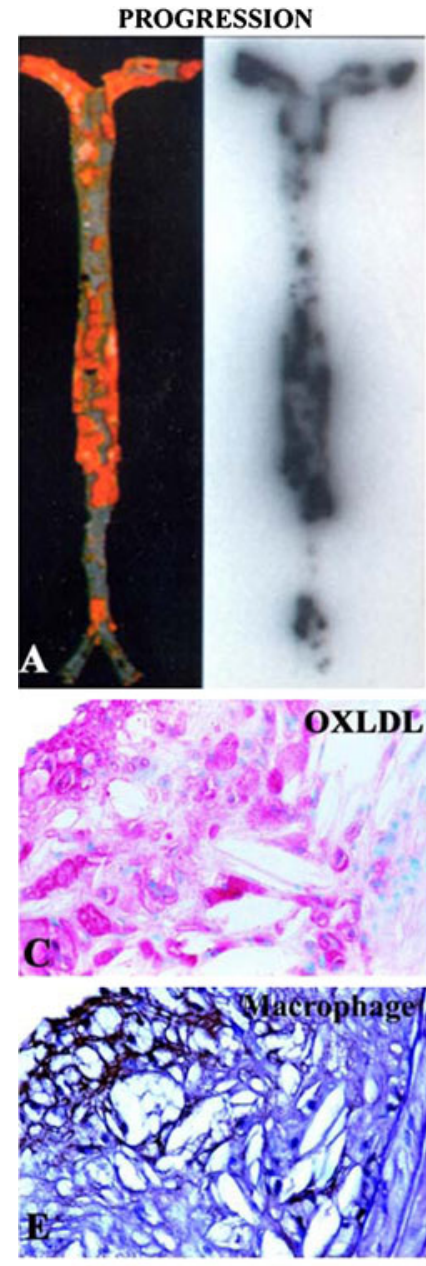

:

G

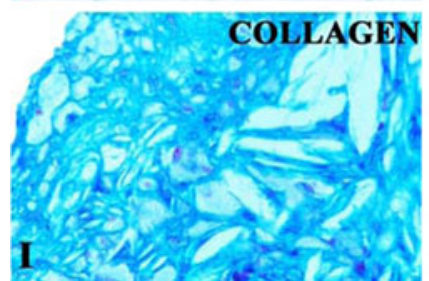

SMC
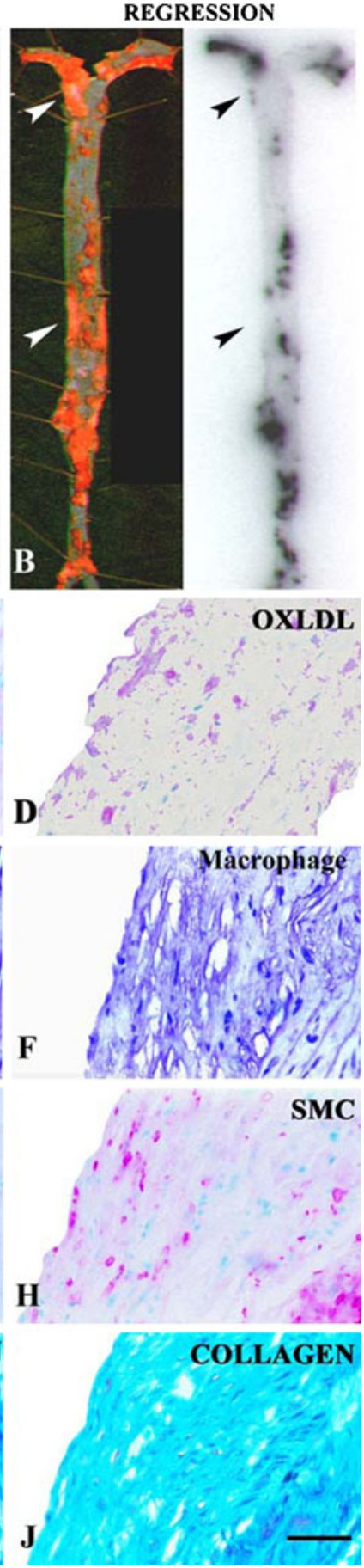

Fig. 4 En face preparation of Sudan-stained mouse aortas (left) and corresponding autoradiographs (right) showing representative examples of intravenously injected ${ }^{125}$ I-MDA2 distribution in the progression (a) and regression (b) groups. Arrowheads depict Sudan-stained areas with diminished ${ }^{125}$ I-MDA2 uptake. Note that there is diminished 125IMDA2 uptake in areas of lipid stained plaques representing loss of available MDA binding sites following regression. Panels $\mathbf{c}-\mathbf{j}$ represent examples of immunostained atherosclerotic lesions from $\mathrm{LDLR}^{-1-}$ mice from the progression (c, e, g, i) and regression $(\mathbf{d}, \mathbf{f}, \mathbf{h}, \mathbf{j})$ groups. Immunostaining was performed for OxLDL, macrophages, smooth muscle cells (SMCs), and collagen. OxLDL and SMCs appear pink/ purple, macrophages black, and collagen bright blue. Scale bar $=50 \mu \mathrm{m}$. (Reprinted with permission from Torzewski et al. [11••]) 
Fig. 5 Schematic of S-acetyl thioglycolic acid

N-hydroxysuccinimide ester (SATA) attachment to antibodies, micelle composition, and attachment of antibodies to micelles. a, Composition of the micelles. b, Modification of the antibodies with the SATA linker to facilitate attachment to the micelles via the maleimide moiety. (Reprinted with permission from Briley-Saebo et al. [22••])

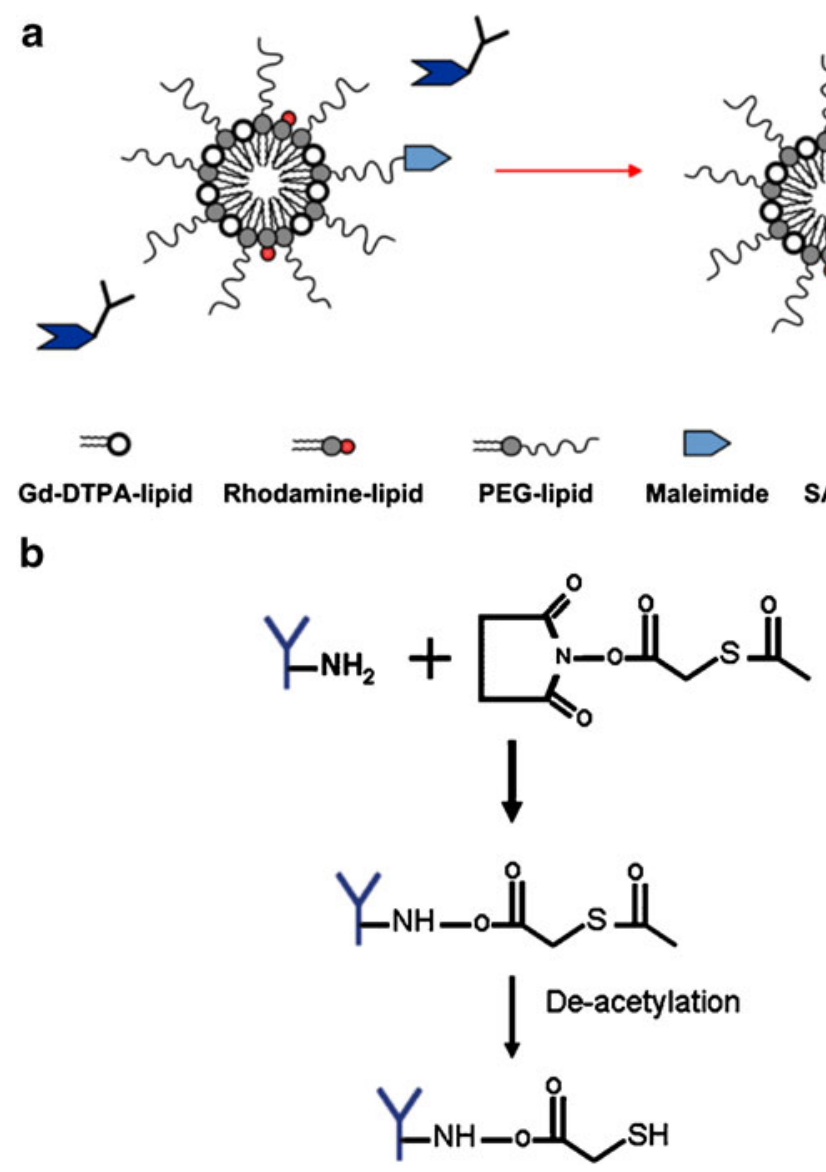

a

(2)

.

.

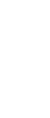


including $\mathrm{LDLR}^{-/-}$and apoE ${ }^{-/-}$mice, cholesterol-fed New Zealand white rabbits, and Watanabe heritable hyperlipidemic (WHHL) rabbits using radiolabeled MDA2 and IK17 antibodies. In a series of experimental studies $[9,10 \bullet, 11 \bullet \bullet]$, it was established that intravenously injected radiolabeled antibodies strongly and preferentially accumulate within lipid-rich, oxidation-rich atherosclerotic lesions, and particularly in areas of increased content of OSE in the extracellular space or on foam cells as documented by concurrent immunostaining. Autoradiography and Sudanstained images of aortas obtained $24 \mathrm{~h}$ after intravenous injection of ${ }^{125} \mathrm{I}-\mathrm{MDA} 2$ into apoE ${ }^{-/-}$mice and WHHL rabbits revealed areas of lipid staining that were nearly identical to the autoradiography signal generated by the accumulation of ${ }^{125}$ I-MDA2 in the atherosclerotic lesions (Fig. 3). The uptake of ${ }^{125}$ I-MDA2, evaluated as the percent of the injected dose, was highest in the aorta compared to all other organs and tissues examined. It was also demonstrated that the uptake of ${ }^{125}$ I-MDA2 in atherosclerotic lesions was proportional to the plaque burden measured by both the percent atherosclerotic lesion area

Fig. 6 Representative abdominal aorta (arrows) enhancement in apoE $\mathrm{E}^{-/}$mice as a function of time following injection of $0.075 \mathrm{mmol} \mathrm{Gd} / \mathrm{Kg}$ of micelles. The vessel to the left of the aorta is the inferior vena cava (IVC). The bright white areas at the abdominal aorta represent magnetic resonance enhancement of atherosclerotic plaque due to accumulation of antibody-tagged $\mathrm{Gd}$ micelles. Although arterial flow was saturated to allow for delineation of the arterial wall, some enhancement in the IVC may be observed due to flow artifacts. (Reprinted with permission from Briley-Saebo et al. [22••]) and aortic weight $[9,10 \bullet]$. Interestingly, in the WHHL rabbits, enhanced uptake of ${ }^{125}$ I-MDA2 was also noted in the spleen and liver, which are known sites of the accumulation of OxPL in humans with nonalcoholic steatohepatitis (NASH), suggesting that it may be possible to noninvasively image NASH with this approach [18]. Furthermore, ${ }^{99 \mathrm{~m}} \mathrm{Tc}-\mathrm{MDA} 2$ successfully noninvasively imaged lipid-rich, oxidation-rich plaques (Fig. 3). Similar qualitative in vivo uptake and autoradiography results were obtained with ${ }^{125} \mathrm{I}$-IK17 $\mathrm{Fab}$ in $\mathrm{LDL}^{-/-}$mice, except for a more rapid plasma clearance due to the smaller size of the Fab fragment [16].

Imaging of the Progression and Regression of Atherosclerosis

The ability to quantitatively image changes in any target in atherosclerotic lesions, in this case OSE in the vessel wall, would be an important feature of any noninvasive imaging technique. This property would allow physicians to not only detect disease but also to monitor disease longitudi-

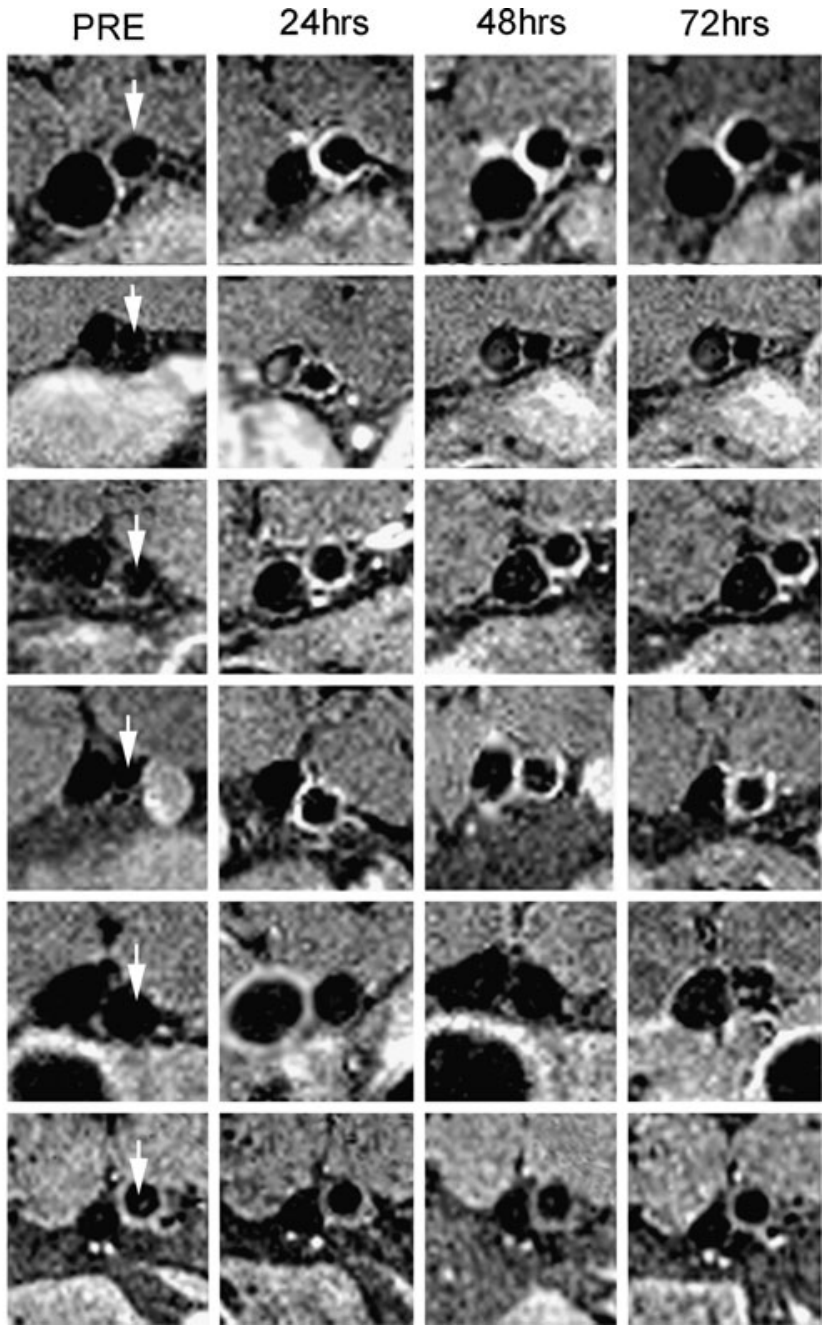


nally over time following dietary, pharmacologic, device, or other therapeutic interventions. We have successfully established that, in principle, oxidation-specific antibodies can perform this type of function. In a dietary regression study, LDLR $^{-/-}$mice were fed a high-cholesterol, high-fat diet for 6 months and either continued on this diet (progression group) or placed back on normal mouse chow (regression group) for an additional 6 months, and each group was then injected with ${ }^{125} \mathrm{I}-\mathrm{MDA} 2$. Uptake of ${ }^{125} \mathrm{I}$ MDA2 was markedly reduced in mouse lesions undergoing atherosclerosis regression and correlated very strongly with features of plaque stabilization, including reduced macrophage content and increased collagen and smooth muscle cell content (Fig. 4) $[10 \bullet, 11 \bullet$ ]. In addition, in this study and another rabbit study, there was evidence obtained by immunostaining that OSE disappeared from the vessel wall following a low-fat diet prior to physical plaque regression, suggesting that this may be a very early mechanism of plaque stabilization $[19,20]$.

These data in atherosclerotic mouse models are consistent with human data on the composition change of human carotid plaques following treatment with pravastatin for 3 months, where immunocytochemical staining by NA59, an antibody binding to the OSE 4-hydroxynonenal (HNE), and its quantitative analysis revealed significantly less immunoreactivity for HNE epitopes in the pravastatintreated group compared to the control group [21]. These data suggest that both dietary and statin-induced lipid- lowering therapy are associated with changes in human carotid plaque composition that favor lesion stability and that these changes can be detected and imaged with oxidation-specific antibodies.

\section{MRI Using Gadolinium Micelles Containing Oxidation-Specific Antibodies}

One of the limitations discovered in using radionuclide techniques with this approach was the modest target-toblood ratios, which were not mediated by diminished plaque uptake of the ${ }^{125} \mathrm{I}$ or ${ }^{99 \mathrm{~m}} \mathrm{Tc}$ radiolabeled antibodies, but instead by the high blood background due to the slow clearance of the radiolabeled antibodies. For translation to clinical imaging, because of the relatively short radiolabel half-life of ${ }^{99 \mathrm{~m}} \mathrm{Tc}$ and the relatively long biological half-life of antibody clearance, an optimal window where the maximal antibody uptake and binding coinciding with the maximal photon flux of ${ }^{99 \mathrm{~m}} \mathrm{Tc}$ was not feasible. This resulted in ${ }^{99 \mathrm{~m}} \mathrm{Tc}$ images that were suboptimal for a quantitative assessment of OSE. Thus far, PET techniques have not been evaluated with this approach.

To overcome this challenge, a series of experiments were performed using an MRI approach where oxidation-specific antibodies were covalently attached to gadolinium (Gd)containing micelles ( $\sim 50$ gadolinium ions per micelle) $[22 \bullet \bullet]$. In short, micelles were prepared using 1,2-distearoyl-sn-glycer-3-phosphoethanolamine-n-methoxy (poly-
Fig. 7 Confocal microscopy $(63 \times)$ of apoE $\mathrm{E}^{-/-}$mouse aortic atherosclerotic plaque following the administration of MDA2micelles and E06-micelles demonstrating nuclei (blue), macrophages (green), and micelles (red). The lower panels represent an atherosclerotic plaque from an $\mathrm{apoE}^{-/-}$mouse not injected with micelles and stained with DAPI, showing the absence of significant autofluorescence $(40 \times)$. (Reprinted with permission from Briley-Saebo et al. $[22 \bullet \bullet])$

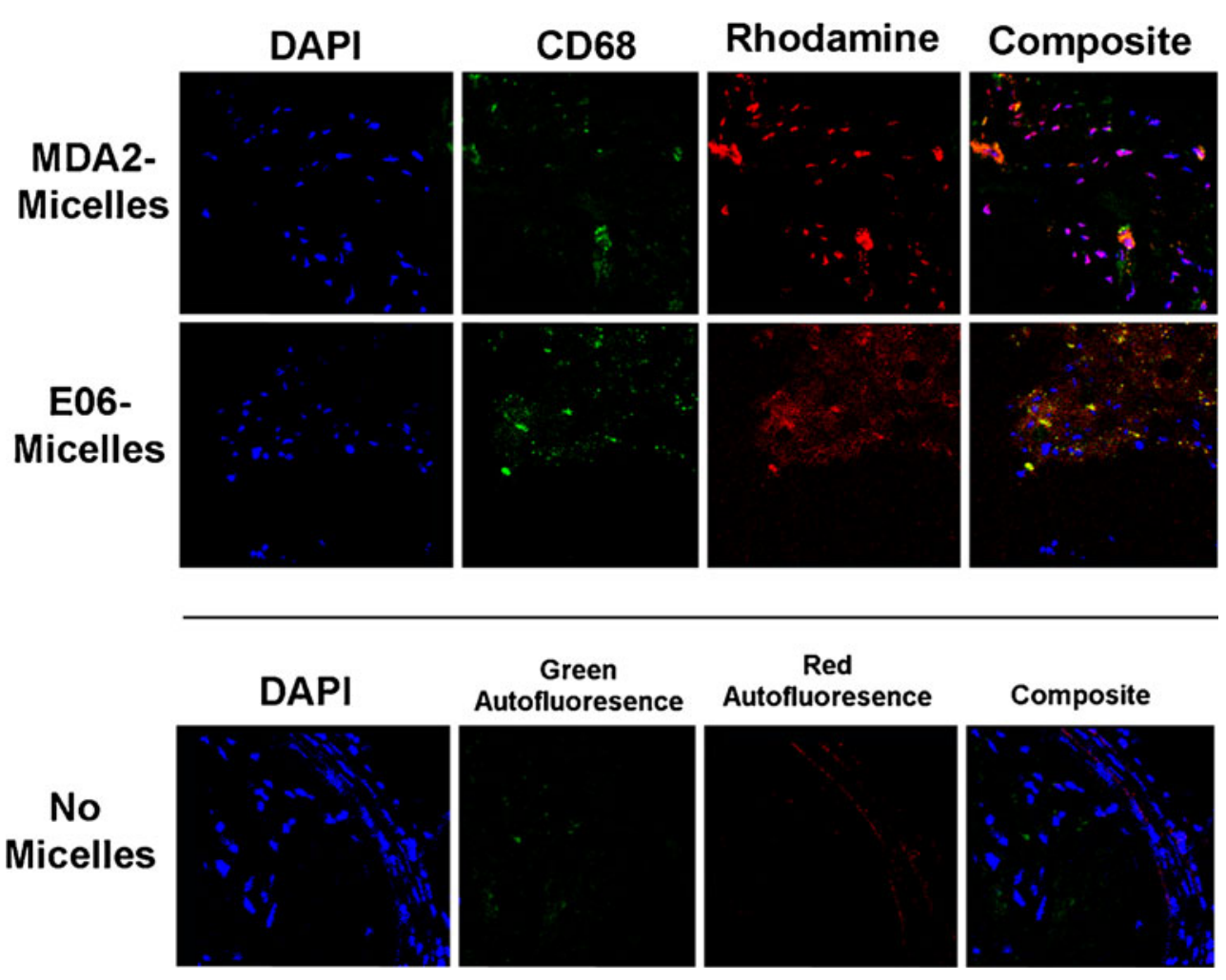




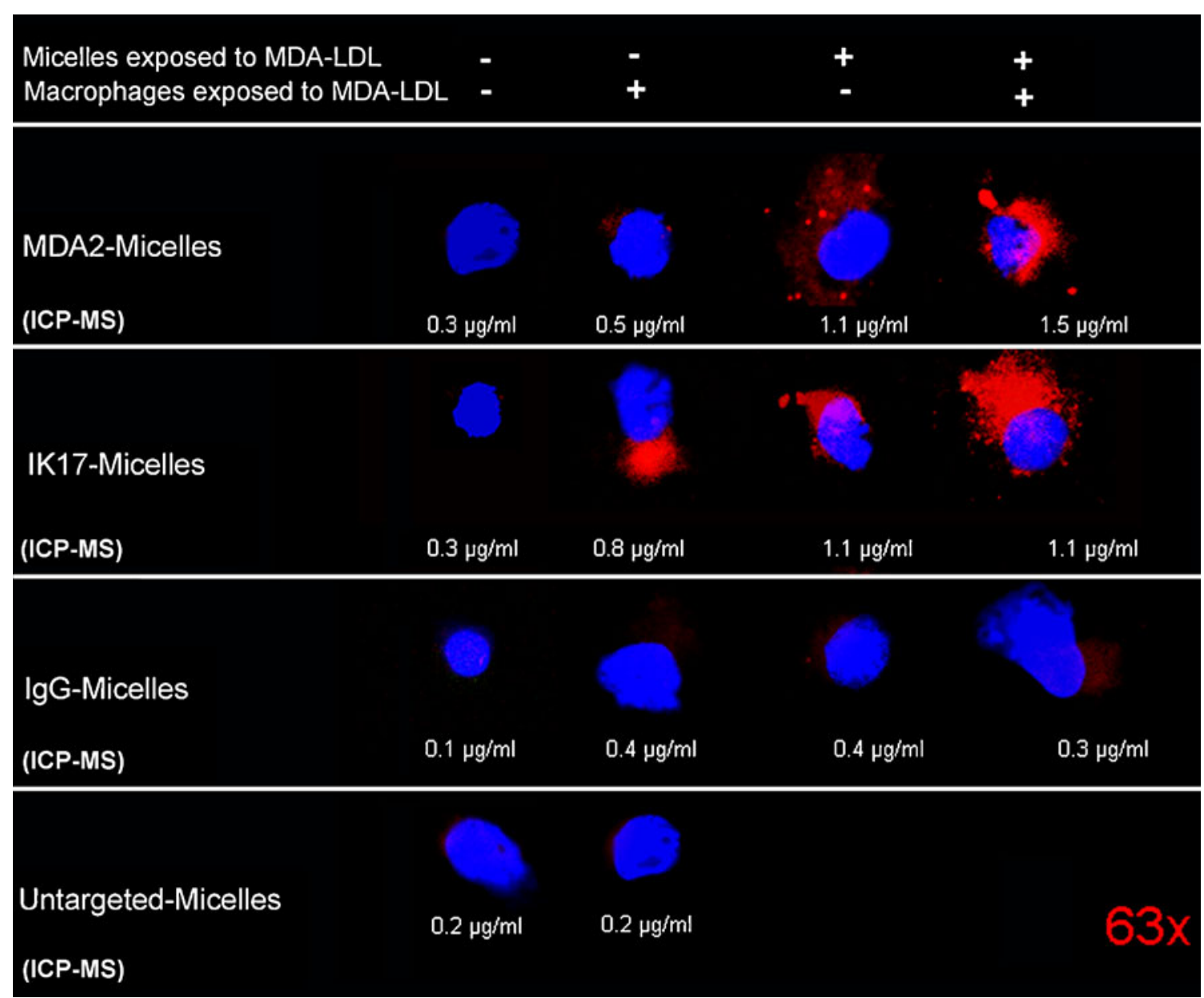

Fig. 8 Confocal microscopy $(63 \times)$ showing the association of micelles with macrophages in in vitro experiments. Macrophages and micelles were either exposed $(+)$ or not exposed (-) to MDA-LDL prior to mixing together in cell culture. Red (rhodamine) represents the presence of micelles and blue (DAPI) macrophage nuclei. The

ethylene glycol-2000), Gd-DTPA-bis, and PEG-malamideDSPE by dissolving in chloroform:methanol with rhodamine added as a fluorescent label (Fig. 5). MDA2-micelles, E06micelles, and IK17-micelles were modified with Sacetylthioglycolic acid N-hydroxysuccinimide ester and then covalently linked to the surface of the gadolinium micelles. The hydrated diameter of the micelles was 14 to $22 \mathrm{~nm}$ and their $\mathrm{rl}$ values at $60 \mathrm{MHz}$ were approximately $10 \mathrm{~s}^{-1} *$ $\mathrm{mmol} / \mathrm{L}^{-1}$ (Table 1 ).

MRI was performed at 9.4 Tesla over a 96-hour time interval after the administration of $0.075 \mathrm{mmol} \mathrm{Gd} / \mathrm{kg}$ micelles. MDA2-micelles and IK17-micelles showed maximal arterial wall uptake at $72 \mathrm{~h}$ and E06-micelles at $96 \mathrm{~h}$, manifested by $125 \%$ to $231 \%$ enhancement in MR signal compared to adjacent muscle in cholesterolfed $\mathrm{apoE}^{-/-}$mice. In vivo imaging revealed significant signal enhancement with all targeted micelles, compared to untargeted micelles or micelles tagged with a nonspecific antibody (Fig. 6). No significant enhancement was numbers under each panel represent gadolinium content measured by inductively coupled plasma mass spectrometry (ICP-MS) normalized to total cell number. (Reprinted with permission from BrileySaebo et al. $[22 \bullet \bullet])$

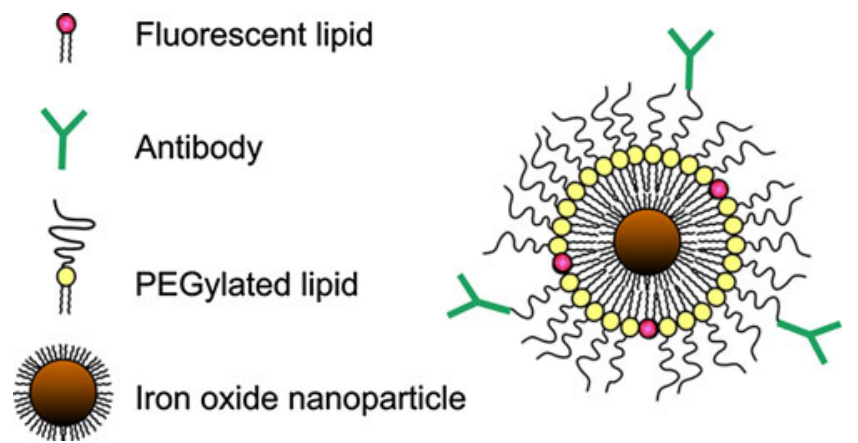

Fig. 9 Schematic diagram of the lipid-coated iron oxide particles. The lipid-coated LUSPIOs were prepared by first synthesizing the monocrystalline and mono-disperse iron core. PEG-DSPE, PEG-malamideDSPE, and liss rhodamine are added at a ratio of $17.3 \mathrm{mg}: 1.3 \mathrm{mg}: 0.12 \mathrm{mg}$ per milligram iron. Antibodies $(0.35 \mathrm{mg} / \mathrm{mg} \mathrm{Fe})$ were attached to the LUSPIO and LSPIO surface via S-acetyl thioglycolic acid Nhydroxysuccinimide ester modification. (Reprinted with permission from Briley-Saebo et al. [28••]) 
observed after administration of either untargeted micelles or IgG micelles or of any micelles in wild-type mice. When excess free MDA2 was pre-injected, the plaque enhancement of MDA2 micelles was significantly reduced to a level comparable to that of untargeted micelles, confirming a specific targeting mechanism. Confocal microscopy confirmed the association of the MDA2 micelles and E06 micelles within the arterial vessel wall of apoE $^{-/-}$mice and colocalization of rhodamine of micelles with markers of macrophages showing uptake of micelles by macrophages (Fig. 7).

The uptake of targeted micelles within macrophages suggested the possibility of extracellular interactions of OxLDL with the targeted micelles. To ascertain this, we incubated macrophages that were pre-exposed to MDALDL with MDA2-micellles that were also pre-incubated with MDA-LDL and measured uptake by macrophages by confocal microscopy and quantitatively by ICP-MS studies (Fig. 8). The qualitative results indicate that when micelles were pre-exposed to MDA-LDL there was limited association of micelles with macrophages (column 1). When the macrophages were pre-exposed to MDA-LDL but the micelles were not there was association of MDA2micelles and IK17-micelles with macrophages (column 2). When the MDA2-micelles and IK17-micelles were preincubated with MDA-LDL but the macrophages were not, there was even greater association of MDA2-micelles and IK17-micelles with macrophages (column 3). Finally, when both macrophages and micelles were pre-exposed to MDALDL, the highest association of MDA2-micelles and IK17micelles with macrophages was noted (column 4). In contrast, minimal association of IgG-micelles or untargeted micelles was noted in any condition. This strongly suggests the mechanism that the entry of micelles within macrophage occurs on activated macrophages when the antibodymicelles interact with extracellular OxLDL and the entire particle is taken up within the macrophage. Studies are underway to assess the role of macrophage scavenger receptors or other uptake pathways, such as macropinocytosis, in the uptake of these targeted micelles.

\section{MRI Using Iron Oxide Particles}

One disadvantage of using gadolinium-based MRI contrast agents is the potential for nephrogenic systemic fibrosis in renally impaired patients following injection of clinically available low-molecular-weight $\mathrm{Gd}$ chelates [23]. Gd is known to come off its chelate at low $(2 \%-3 \%)$ but measurable rates, and free Gd can be toxic to cells and induce apoptosis [24]. Gd also has lower relaxivity compared to iron oxide nanoparticles. To circumvent this issue, we have recently explored the use of biocompatible iron oxide nanoparticles containing oxidation-specific antibodies to target them to atherosclerotic lesions, and specifically to macrophages. Prior studies with dextrancoated ultrasmall iron oxide particles (USPIOs) have passively targeted intraplaque macrophages [25]. These USPIOs are desirable from a safety point of view, since cells associated with the reticuloendothelial system are able to safely eliminate iron [26]. However, this passive targeting strategy may be suboptimal since these materials require slow infusion and long time-intervals between administration and MRI ( $>24 \mathrm{~h})$ [27].

We therefore hypothesized that pegylated, lipid-coated iron oxide particles (without dextran) targeted to oxidation-specific epitopes may increase the clinical utility of the iron oxide platform for MRI of vulnerable atherosclerotic plaques. Lipidcoated ultra-small superparamagnetic iron particles (LUSPIO, $<20 \mathrm{~nm}$ ) and superparamagnetic iron particles (LSPIO, $<40 \mathrm{~nm}$ ) were conjugated with antibodies targeted to either MDA-lysine or oxidized phospholipid epitopes (Fig. 9). All formulations were characterized and their in vivo efficacy

Table 2 Physical and chemical properties of lipid-coated ultra-small superparamagnetic iron particles (LUSPIO) and superparamagnetic iron particles (LSPIO)

\begin{tabular}{|c|c|c|c|c|c|c|}
\hline Formulation & Size, $n m$ & $\mathrm{r} 1, s^{-1} m M^{-1}$ & $\mathrm{r} 2, s^{-1} m M^{-1}$ & $\begin{array}{l}\text { Blood half-life } \\
\text { apoE }^{-/-}, h\end{array}$ & $\begin{array}{l}\text { Blood half-life } \\
\text { WT, } h\end{array}$ & $\%$ ID in liver (24 hrs p.i) \\
\hline Untargeted LUSPIO & $10 \pm 3$ & $14 \pm 1$ & $35 \pm 2$ & 1.52 & 1.41 & 25 \\
\hline Untargeted LSPIO & $35 \pm 5$ & $12 \pm 1$ & $103 \pm 4$ & 1.02 & 1.01 & 35 \\
\hline MDA2 LUSPIO & $14 \pm 3$ & $13 \pm 1$ & $37 \pm 2$ & 9.01 & 1.55 & 31 \\
\hline MDA2 LSPIO & $38 \pm 4$ & $11 \pm 1$ & $117 \pm 5$ & 7.28 & 1.12 & 37 \\
\hline IK17 LUSPIO & $12 \pm 2$ & $14 \pm 1$ & $35 \pm 2$ & 9.12 & & 31 \\
\hline IK17 LSPIO & $36 \pm 4$ & $10 \pm 1$ & $106 \pm 5$ & 7.30 & & 34 \\
\hline E06 LUSPIO & $16 \pm 4$ & $12 \pm 1$ & $38 \pm 2$ & 9.32 & & 30 \\
\hline E06 LSPIO & $39 \pm 5$ & $11 \pm 1$ & $119 \pm 6$ & 7.42 & & 35 \\
\hline
\end{tabular}

All sizes are based upon the weighted number averages. The relaxivities shown were obtained in buffer at $60 \mathrm{MHz}$ and $40^{\circ} \mathrm{C}$. All blood half-lives and percent injected dose (\%ID) in the liver were obtained in apoE $\mathrm{E}^{-/-}$or wild-type (WT) mice after injection of a 3.9-mg Fe/Kg dose 
evaluated in apoE $\mathrm{E}^{-/-}$mice $24 \mathrm{~h}$ after bolus administration of a $3.9 \mathrm{mg} \mathrm{Fe} / \mathrm{kg}$ dose using MRI (Table 2) [28••].

All MRI was performed at 9.4 Tesla using an $89-\mathrm{mm}$ bore system operating at a proton frequency of $400 \mathrm{MHz}$ (Bruker Instruments, Billerica, MA) prior to and 24 hours after the administration of a $3.9-\mathrm{mg} \mathrm{Fe} / \mathrm{Kg}$ dose. In order to obtain in vivo R2* maps, multiple echo GRE sequences with the following pulse sequence parameters were applied: $\mathrm{TR}=29.1 \mathrm{~ms}, \mathrm{TE}=5.1 \mathrm{~ms}$ to $10 \mathrm{~ms}(n=5)$, flip angle $=30^{\circ}$, number of signal averages $(\mathrm{NEX})=6$, in-plane resolution $=$
$0.098 \mathrm{~mm}^{2}$, and $100 \% \mathrm{z}$-rephasing gradient. Twenty slices were acquired from the level of the renal arteries to the iliac bifurcation. R2*-maps were generated for matched pre and post images on a pixel-by-pixel basis using a custom Matlab program (The Mathworks, R2007b). The signal intensity associated with each pixel was normalized to the standard deviation of adjacent noise (placed above the spine of the mouse) prior to linear fitting of the signal-to-noise ratio versus echo time (TE). R2* values were then obtained using regions of interest drawn on the arterial wall on slices
Fig. 10 Representative in vivo LUSPIO MRIs obtained prior to (pre) and $24 \mathrm{~h}$ after administration of a $3.9-\mathrm{mg} \mathrm{Fe} / \mathrm{Kg}$ dose in $\mathrm{apoE}^{-/-}$mice. The yellow arrows indicate the position of the lumen associated with the abdominal aorta. All GRE images shown were obtained using an echo time of $7 \mathrm{~ms}$. Corresponding white marker GRASP images are also shown. For the competitive inhibition results, apoE ${ }^{-/}$mice were administered free excess MDA2 antibody at the time of MDA2labeled LUSPIO injection. Matched histology sections show iron deposition (blue) within foam cells associated with the arterial wall. Relative percent changes in the $\mathrm{R} 2 *$ values associated with the arterial wall following administration of the LUSPIO formulations are also shown (bottom panel). The error bars reflect the standard deviation associated with mean value obtained for mice receiving untargeted LUSPIOs and $n=6$ mice receiving MDA2 or E06labeled LUSPIOs. (Reprinted with permission from BrileySaebo et al. $[28 \bullet \bullet])$

PRE

POST

PERL'S

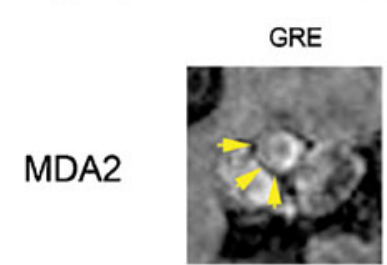

\section{GRASP}

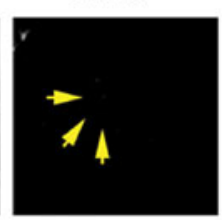

Compet.

Inhibition
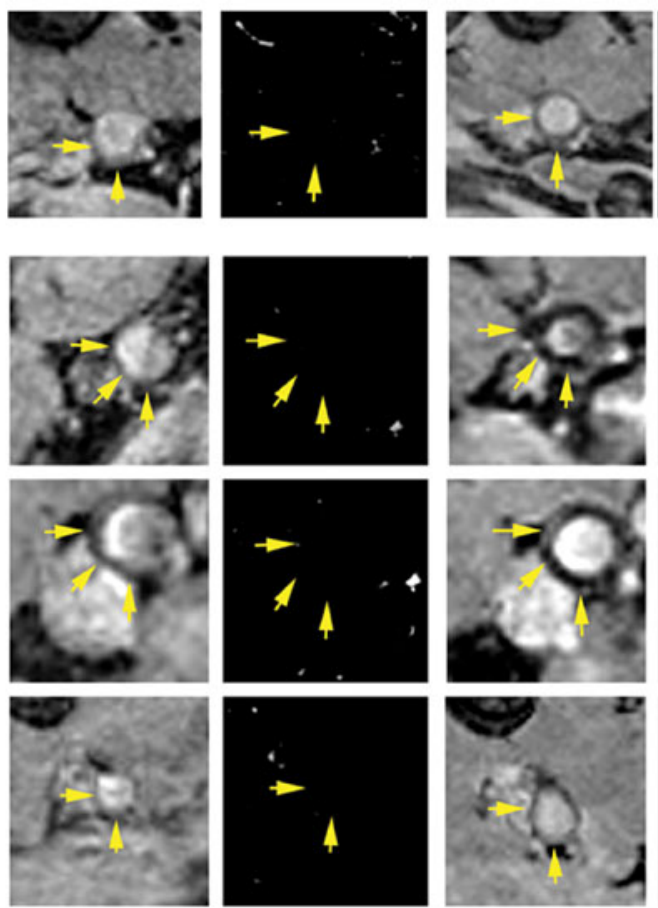

LUSPIO

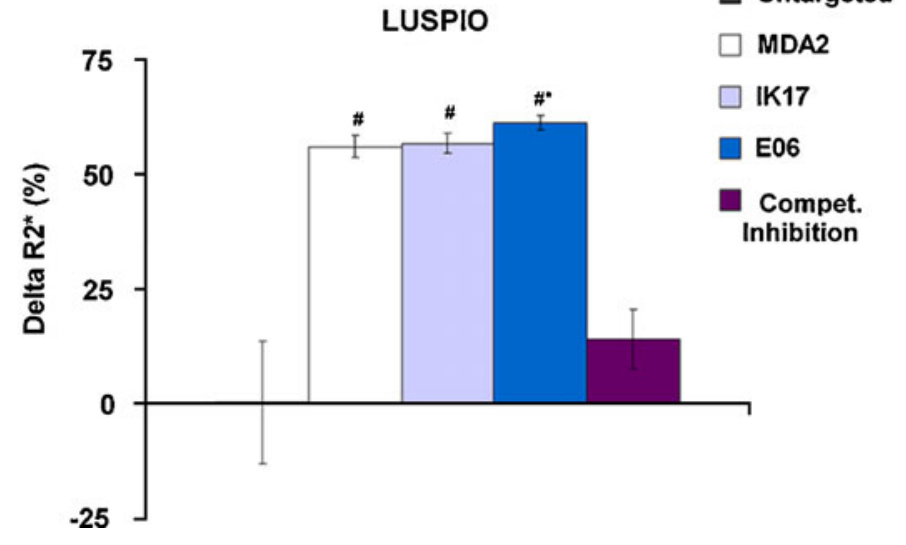

GRASP
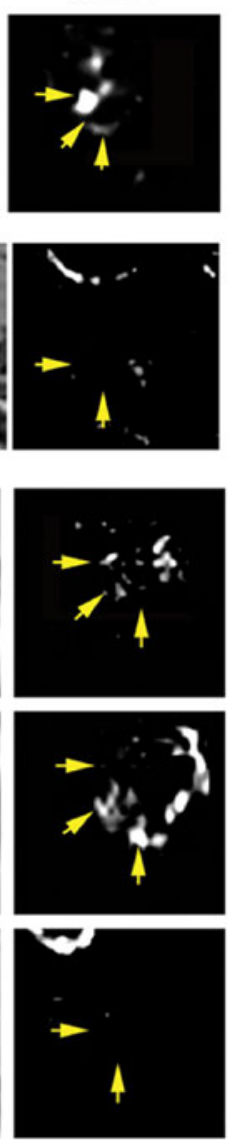

Untarg.

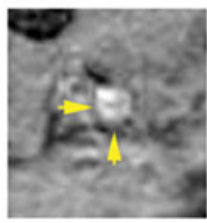

Untargeted

MDA2

$\square$ IK17

Compet.
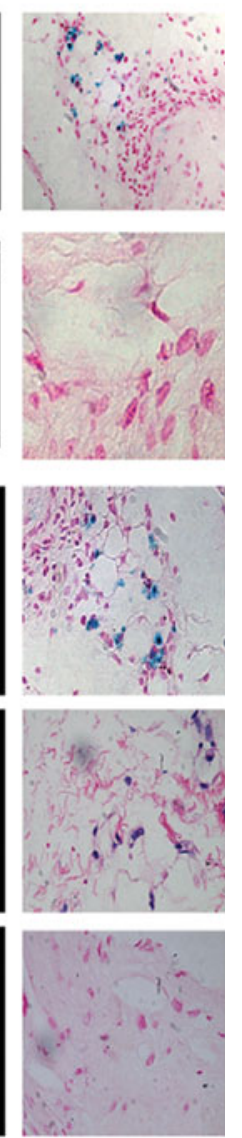


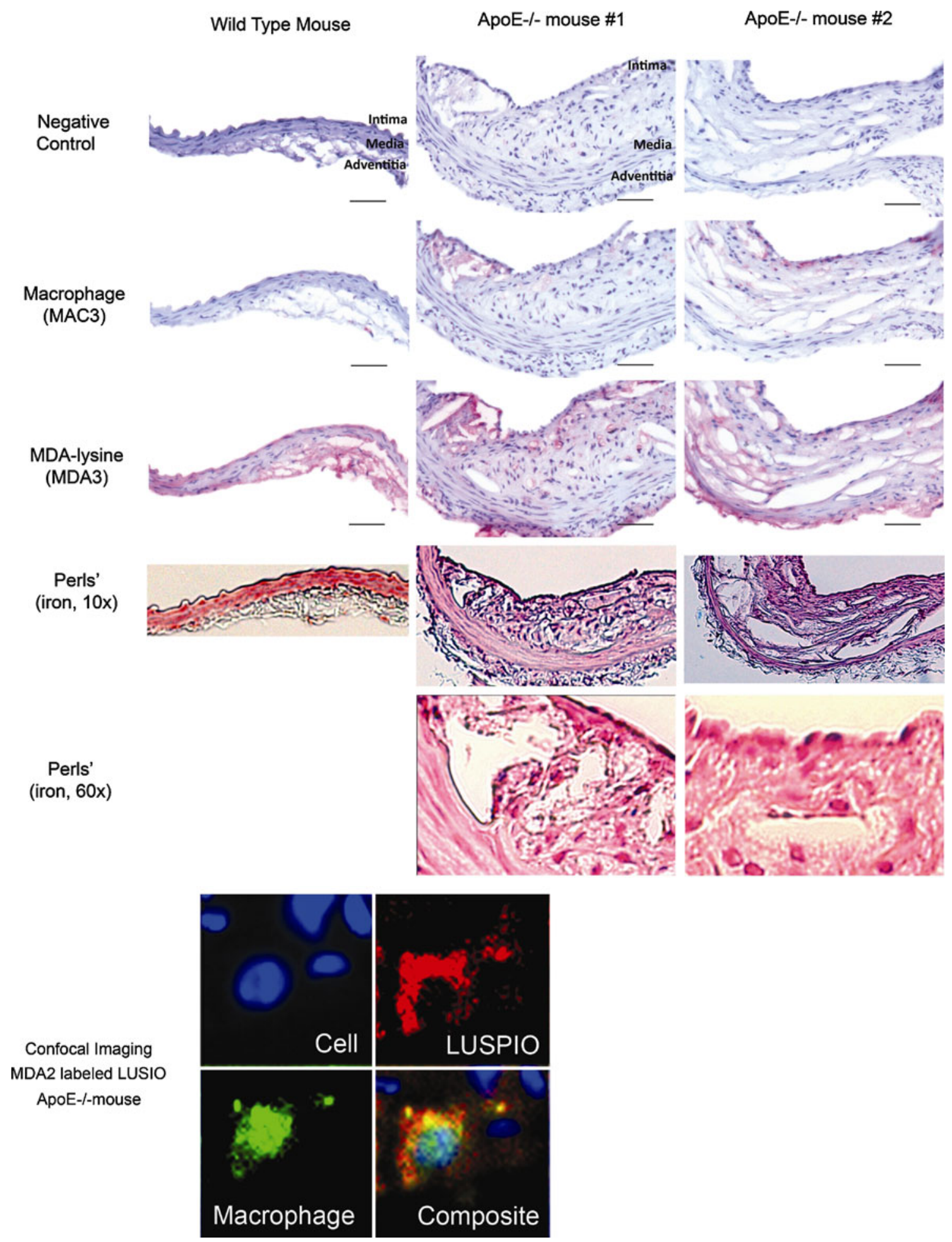

Fig. 11 Immunohistochemistry (top panel) and confocal microscopy (bottom panel) of MDA2-labeled LUSPIOs in the arterial wall of $\mathrm{apoE}^{-/-}$and wild-type mice. The arterial wall was stained for MDAlysine (MDA3 staining), macrophages (MAC3), and iron oxide
(Perl's) deposition. Confocal microscopy was using a multichannel laser so that co-localization between the cell nuclei (blue), macrophages (green), and MDA2-labeled LUSPIOs (red) could be performed. (Reprinted with permission from Briley-Saebo et al. [28••]) 
( $n>5$ ) exhibiting either R2* modulation post contrast or arterial wall thickening, indicative of plaque deposition. The relative percent changes in the $\mathrm{R} 2 *$ values were determined as $\%$ change $=((R 2 *$ post $-R 2 *$ pre $) / R 2 *$ post $) * 100$.

Immediately following GRE acquisition, a GRASP sequence was applied using $50 \%$ of the z-rephasing gradient. GRASP is extremely useful when trying to determine if MR signal loss is due to iron oxide deposition or other endogenous artifacts (motion, partial voluming, and perivascular effects) that may also promote signal loss. GRASP cannot be used alone, however, since this sequence does not provide adequate anatomic information. In similarity to GRE sequences, GRASP signal may be observed in lymphatic tissue that may also sequester the iron oxide particles. However, this sequence is extremely useful to differentiate between iron oxide deposition and artifacts that are often present when imaging the arterial wall. Blooming artifacts cause the GRE images to sometimes show uniform signal loss while the GRASP images show focal, nonuniform enhancement. Phantom studies have indicated that GRASP sequence is less susceptible to blooming artifacts since very localized field inhomogeneities are required to produce strong GRASP signal. If the iron oxide particles are uniformly distributed or if the field distribution is large, then the GRASP signal is reduced since the local susceptibility differences cannot be matched.

In vivo imaging data were correlated with the presence of oxidation-specific epitopes using immunohistochemistry. MRI of atherosclerotic lesions, as manifested by signal loss, was observed following administration of targeted LUSPIOs (Fig. 10). In vivo competitive inhibition studies showed a $74.9 \%(P=0.0002)$ reduction in $\mathrm{R} 2 *$ for mice administered free MDA2 at the time of MDA2-labeled LUSPIO micelle injection, again implying a specific targeting mechanism. Limited signal attenuation was observed for untargeted LUSPIOs. Additionally, no significant arterial wall uptake was observed for targeted or untargeted LSPIOs due to their limited ability to penetrate the vessel wall. Immunohistochemistry of aortas of apoE $\mathrm{E}^{-/-}$ mice administered the MDA2-labeled LUSPIO showed strong correlation between iron oxide (Perls' staining) and MDA-lysine epitope deposition (Fig. 11). Limited LUSPIO and MDA-lysine was observed in age-matched wild-type mice. Additionally, confocal microscopy confirmed the uptake of the oxidation-specific targeted LUSPIOs (rhodamine labeled) within atherosclerotic lesions and specifically within intraplaque macrophages/foam cells (anti-CD68 labeled) 24 hours post-injection. Rhodamine-labeled targeted LUSPIOs were not observed in the extracellular matrix. These results are consistent with the findings reported for MDA2-Gd micelles [22••]. Additionally, strong co-localization between MDA epitopes and Perls' Prussian blue staining was observed, thereby confirming the pres- ence of the targeted LUSPIOs in macrophages/foam cells enriched in oxidation-specific epitopes.

These pegylated nanoparticles do not appear to be selectively taken up by macrophages unless they also contain an oxidation-specific antibody. In this way, they appear to selectively accumulate primarily within lipid-rich macrophage foam cells, perhaps due to binding extracellular OxLDL at these sites or to OxLDL bound on macrophage scavenger receptors that mediate particle uptake.

\section{Conclusions}

These sets of studies demonstrate that it is feasible to noninvasively image and quantitate oxidation-specific epitopes associated with atherosclerosis with both radionuclide and MRI techniques, particularly with biocompatible iron oxide nanoparticles that specifically target macrophages. The OSE targets are biologically validated as being strong markers of the presence and progression of atherosclerosis. The antibodytargeting agents appear to not only detect plaque burden, but importantly plaque composition, particularly plaque enriched in oxidized lipids and activated macrophages. Future studies will focus on translating these observations to human applications using human antibody fragments, such as single chain IK17, which have particular appeal for detecting advanced OSE in human vulnerable and ruptured plaques. The ability to detect and quantify OSE in humans will allow detection of high-risk plaques and provide the tools to allow surveillance following a variety of therapeutic interventions. This approach will have particular appeal initially in the carotid and peripheral circulation and, with advances in imaging techniques, possibly in coronary arteries as well.

Disclosure K. C. Briley-Saebo: none; Y. S. Cho: none; S. Tsimikas: board member (no salary) and stock/stock options for Atherotope Inc.

Open Access This article is distributed under the terms of the Creative Commons Attribution Noncommercial License which permits any noncommercial use, distribution, and reproduction in any medium, provided the original author(s) and source are credited.

\section{References}

Papers of particular interest, published recently, have been highlighted as:

- Of importance

-• Of major importance

1. - Navab M, Ananthramaiah GM, Reddy ST, Van Lenten BJ, Ansell BJ, Fonarow GC, Vahabzadeh K, Hama S, Hough G, 
Kamranpour N, Berliner JA, Lusis AJ, Fogelman AM. Thematic review series: The Pathogenesis of atherosclerosis: The oxidation hypothesis of atherogenesis: the role of oxidized phospholipids and HDL. J Lipid Res. 2004;45:993-1007. This is an excellent review on the pathogenesis of atherosclerosis.

2. Miller YI, Choi SH, Fang L, Tsimikas S. Lipoprotein modification and macrophage uptake: role of pathologic cholesterol transport in atherogenesis. Subcell Biochem. 2010;51:229-251.

3. - Glass CK, Witztum JL. Atherosclerosis. The road ahead. Cell. 2001;104:503-516. This is an excellent review on the role of oxidation in atherosclerosis.

4. Palinski W, Rosenfeld ME, Ylä-Herttuala S, Gurtner GC, Socher SS, Butler SW, Parthasarathy S, Carew TE, Steinberg D, Witztum JL. Low density lipoprotein undergoes oxidative modification in vivo. Proc Natl Acad Sci USA. 1989;86:1372-1376.

5. Palinski W, Tangirala RK, Miller E, Young SG, Witztum JL. Increased autoantibody titers against epitopes of oxidized LDL in LDL receptor-deficient mice with increased atherosclerosis. Arterioscler Thromb Vasc Biol. 1995;15:1569-1576.

6. •- Hartvigsen K, Chou MY, Hansen LF, Shaw PX, Tsimikas S, Binder CJ, Witztum JL. The role of innate immunity in atherogenesis. J Lipid Res. 2009;50 Suppl:S388-S393. This is an excellent review on the role of the innate immune system and atherosclerosis.

7. Libby P. Inflammation in atherosclerosis. Nature. 2002;420:868-874.

8. Rosenfeld ME, Palinski W, Ylä-Herttuala S, Butler S, Witztum JL. Distribution of oxidation specific lipid-protein adducts and apolipoprotein B in atherosclerotic lesions of varying severity from WHHL rabbits. Arteriosclerosis. 1990;10:336-349.

9. Tsimikas S, Palinski W, Halpern SE, Yeung DW, Curtiss LK, Witztum JL. Radiolabeled MDA2, an oxidation-specific, monoclonal antibody, identifies native atherosclerotic lesions in vivo. $J$ Nucl Cardiol. 1999;6:41-53.

10. •Tsimikas S, Shortal BP, Witztum JL, Palinski W. In vivo uptake of radiolabeled MDA2, an oxidation-specific monoclonal antibody, provides an accurate measure of atherosclerotic lesions rich in oxidized LDL and is highly sensitive to their regression. Arterioscler Thromb Vasc Biol. 2000;20:689-697. This paper represents the first description of using oxidation-specific antibodies for imaging atherosclerosis.

11. •• Torzewski M, Shaw PX, Han KR, Shortal B, Lackner KJ, Witztum JL, Palinski W, Tsimikas S. Reduced in vivo aortic uptake of radiolabeled oxidation-specific antibodies reflects changes in plaque composition consistent with plaque stabilization. Arterioscler Thromb Vasc Biol. 2004;24:2307-2312. This paper represents the first description of using oxidation-specific antibodies for detecting atherosclerosis regression and plaque stabilization.

12. Friedman P, Hörkkö S, Steinberg D, Witztum JL, Dennis EA. Correlation of antiphospholipid antibody recognition with the structure of synthetic oxidized phospholipids: Importance of Schiff base formation and Aldol condensation. J Biol Chem. 2001;277:7010-7020.

13. Hõrkkõ S, Bird DA, Miller E, Itabe H, Leitinger N, Subbanagounder G, Berliner JA, Friedman P, Dennis EA, Curtiss LK, Palinski W, Witztum JL. Monoclonal autoantibodies specific for oxidized phospholipids or oxidized phospholipid-protein adducts inhibit macrophage uptake of oxidized low-density lipoproteins. $J$ Clin Invest. 1999;103:117-128.

14. Shaw PX, Hörkkö S, Chang MK, Curtiss LK, Palinski W, Silverman GJ, Witztum JL. Natural antibodies with the T15 idiotype may act in atherosclerosis, apoptotic clearance, and protective immunity. J Clin Invest. 2000;105:1731-1740.

15. Binder CJ, Horkko S, Dewan A, Chang MK, Kieu EP, Goodyear CS, Shaw PX, Palinski W, Witztum JL, Silverman GJ. Pneumococcal vaccination decreases atherosclerotic lesion formation: molecular mimicry between Streptococcus pneumoniae and oxidized LDL. Nat Med. 2003;9:736-743.

16. Shaw PX, Hörkkö S, Tsimikas S, Chang MK, Palinski W, Silverman GJ, Chen PP, Witztum JL. Human-derived anti- oxidized LDL autoantibody blocks uptake of oxidized LDL by macrophages and localizes to atherosclerotic lesions in vivo. Arterioscler Thromb Vasc Biol. 2001;21:1333-1339.

17. Burke A, Cresswell N, Kolodgie F, Virmani R, Tsimikas S. Increased expression of oxidation-specific epitopes and $\mathrm{Lp}(\mathrm{a})$ reflect unstable plaques in human coronary arteries. J Am Coll Cardiol. 2008;49:A299.

18. Ikura Y, Ohsawa M, Suekane T, Fukushima H, Itabe H, Jomura H, Nishiguchi S, Inoue T, Naruko T, Ehara S, Kawada N, Arakawa T, Ueda M. Localization of oxidized phosphatidylcholine in nonalcoholic fatty liver disease: impact on disease progression. Hepatology. 2006;43:506-514.

19. Aikawa M, Sugiyama S, Hill CC, Voglic SJ, Rabkin E, Fukumoto Y, Schoen FJ, Witztum JL, Libby P. Lipid lowering reduces oxidative stress and endothelial cell activation in rabbit atheroma. Circulation. 2002;106:1390-1396.

20. Tsimikas S, Aikawa M, Miller FJ, Jr., Miller ER, Torzewski M, Lentz SR, Bergmark C, Heistad DD, Libby P, Witztum JL. Increased plasma oxidized phospholipid:apolipoprotein B-100 ratio with concomitant depletion of oxidized phospholipids from atherosclerotic lesions after dietary lipid-lowering: a potential biomarker of early atherosclerosis regression. Arterioscler Thromb Vasc Biol. 2007;27:175-181.

21. Crisby M, Nordin-Fredriksson G, Shah PK, Yano J, Zhu J, Nilsson J. Pravastatin treatment increases collagen content and decreases lipid content, inflammation, metalloproteinases, and cell death in human carotid plaques: Implications for plaque stabilization. Circulation. 2001;103:926-933.

22. •• Briley-Saebo KC, Shaw PX, Mulder WJ, Choi SH, Vucic E, Aguinaldo JG, Witztum JL, Fuster V, Tsimikas S, Fayad ZA. Targeted molecular probes for imaging atherosclerotic lesions with magnetic resonance using antibodies that recognize oxidation-specific epitopes. Circulation. 2008;117:3206-3215. This paper represents a quantum leap in imaging quality using Gd-micelles containing oxidation-specific antibodies coupled with MRI approaches. It also demonstrates that these micelles strongly accumulate within macrophages in atherosclerotic lesions.

23. Pedersen M. Safety update on the possible causal relationship between gadolinium-containing MRI agents and nephrogenic systemic fibrosis. J Magn Reson Imaging. 2007;25:881-883.

24. Ide M, Kuwamura M, Kotani T, Sawamoto O, Yamate J. Effects of gadolinium chloride $(\mathrm{GdCl}(3))$ on the appearance of macrophage populations and fibrogenesis in thioacetamide-induced rat hepatic lesions. J Comp Pathol. 2005;133:92-102.

25. Trivedi RA, King-Im JM, Graves MJ, Cross JJ, Horsley J, Goddard MJ, Skepper JN, Quartey G, Warburton E, Joubert I, Wang L, Kirkpatrick PJ, Brown J, Gillard JH. In vivo detection of macrophages in human carotid atheroma: temporal dependence of ultrasmall superparamagnetic particles of iron oxide-enhanced MRI. Stroke. 2004;35:1631-1635.

26. Briley-Saebo K, Bjornerud A, Grant D, Ahlstrom H, Berg T, Kindberg GM. Hepatic cellular distribution and degradation of iron oxide nanoparticles following single intravenous injection in rats: implications for magnetic resonance imaging. Cell Tissue Res. 2004;316:315-323.

27. Tang T, Howarth SP, Miller SR, Trivedi R, Graves MJ, King-Im JU, Li ZY, Brown AP, Kirkpatrick PJ, Gaunt ME, Gillard JH. Assessment of inflammatory burden contralateral to the symptomatic carotid stenosis using high-resolution ultrasmall, superparamagnetic iron oxide-enhanced MRI. Stroke. 2006;37:2266-2270.

28. •• Briley-Saebo KC, Cho YS, Shaw PX, Ryu SK, Mani V, Dickson S, Izadmehr E, Green S, Fayad ZA, Tsimikas S (2010) Targeted Iron Oxide Particles For In Vivo Magnetic Resonance Detection of Atherosclerotic Lesions With Antibodies Directed to OxidationSpecific Epitopes. J Am Coll Cardiol. doi:10.1016/j.jacc.2010.09. 023. This study advances the concept of using MRI approaches to image oxidation-specific epitopes to biocompatible iron oxide nanoparticles that have a predilection for intraplaque macrophages. 